\title{
Environmentally friendly method for regeneration of copper chloride acidic solutions used in etching of printed circuits
}

\author{
Dorota Kopyto ${ }^{1,}{ }^{,}$, Wit Baranek $^{1}$, Zbigniew Myczkowski ${ }^{1}$, Katarzyna Leszczyńska-Sejda ${ }^{1}$, Michat Drzazga ${ }^{1}$, \\ Maciej Matusewicz ${ }^{2}$, Tadeusz Matusewicz ${ }^{2}$, and Wojciech Matusewicz ${ }^{2}$ \\ ${ }^{1}$ Institute of Non Ferrous Metals (IMN), Hydrometallurgy Department, ul. Sowińskiego 5, 44-100 Gliwice, Poland \\ ${ }^{2}$ MATUSEWICZ Budowa Maszyn S.A., ul. Lwowska 40, 59-620 Gryfów Śląski, Poland
}

\begin{abstract}
Etching of copper with acidic $\mathrm{CuCl}_{2}$ solution is a widely used chemical method in printed circuits production. During the process, the solution is enriched in $\mathrm{Cu}(\mathrm{I})$ ions, resulting in reduction and then loss of etching bath capacity. In order to ensure the required etching kinetics, the solution is regenerated by oxidation of $\mathrm{Cu}(\mathrm{I})$ to $\mathrm{Cu}(\mathrm{II})$. The industrially applied $\mathrm{Cu}(\mathrm{I})$ oxidants are, e.g.: $\mathrm{Cl}_{2}$, chlorates. Their application is expensive and associated with drawbacks related to health, safety and environmental hazards (e.g. $\mathrm{Cl}_{2}$ emission). In the result of long-standing cooperation between the IMN and MATUSEWICZ Budowa Maszyn, an innovative, original and environmentally friendly method of acidic solutions regeneration used during printed circuits etching was developed. A new-type reactor equipped with oxidation monitoring-control systems using oxygen or oxygen-enriched air was applied. The reactor construction enables to run the process with oxygen circulation in the reactor, ensures full oxygen utilisation in the regeneration process, achievement of the required performance and process rate, and eliminates expensive, hazardous and often toxic reagents. This is an innovative method, and since there are no analogous technologies currently known and used in Europe and worldwide, the presented method is technologically, economically and ecologically unrivalled.
\end{abstract}

\section{Introduction}

Acidic aqueous solution of copper(II) chloride is one of the basic etching agents used in chemical processing of metallic surfaces, e.g. in production of printed electronic circuits. This solution is characterised by very high dissolution yield of metallic copper. Its additional advantage, comparing to iron(III) chloride solutions widely used in the past or ammonia solutions, is better stability and control of the set process parameters and compliance with environmental protection requirements. During the process of printed board etching part of the metallic copper present on the processed boards is dissolved. As a result, concentration of copper(I) cations in the etching solution increases. It causes reduction and finally loss of bath etching ability. In order to maintain high efficiency and stable rate of printed circuits etching it is necessary to regenerate etching solution. It is done by oxidation of monovalent copper to divalent one and removal of copper excess from the solution.

Oxidants of $\mathrm{Cu}(\mathrm{I})$ used in industry are: hydrogen peroxide $\left(\mathrm{H}_{2} \mathrm{O}_{2}\right)$, gaseous chlorine $\left(\mathrm{Cl}_{2}\right)$, sodium chlorate $\left(\mathrm{NaClO}_{3}\right)$ [1-5]. Application of these oxidants is expensive and connected with other disadvantages like: health, safety and environmental issues (e.g. due to chlorine emissions) as well as keeping optimum composition of etching solution. Regeneration trials using air, pure oxygen or mixture of oxygen and certain ozone amount were also performed [6]. However, they did not give positive results due to too low reaction rate and process efficiency. It was caused by insufficient dispersion of gaseous oxidant in water phase.

Printed circuits industry is a huge market strictly connected to production of electronic and electric equipment and components. Currently systematic growth of global income from printed circuit board (PCB) may be observed. It is estimated that the market is worth $\$ 78-85$ billion. Despite huge and noticeable demand on PCBs neither production efficiency nor environmental protection standards improvement were observed. Every year, millions litres of solutions are used for etching of printed circuits. All the amount need to be regenerated and returned to the process. Therefore, it is so important to find economic, environmentally-friendly and efficient method of etching solution regeneration.

Currently, technology for acid etching solution regeneration using oxygen and/or oxygen-enriched air is not offered on the market. However, it is the most attractive and promising method. It has the highest application potential due to availability of oxidising agent, safety of its application, no emission of additional unwanted compounds and gases as well as low operational costs. In order to implement this method to industrial practice it is necessary to ensure sufficient rate

\footnotetext{
Corresponding author: dorotak@imn.gliwice.pl
} 
and efficiency of monovalent copper oxidation by e.g. application of proper reactor, which can be able to enhance oxygen dispersion in a solution.

Taking into account above-mentioned requirements company Matusewicz Budowa Maszyn S.A. (company with several years of experience in construction of equipment used in electrotyping) initiated an innovative action within the project POIG.01.04.00-02-049/11 entitled: „Development of new regeneration method for acidic copper(II) chloride solutions used in etching of printed circuits" (original Polish title :,Opracowanie nowej metody regeneracji kwaśnych roztworów chlorku miedziowego stosowanych $\mathrm{w}$ procesie trawienia obwodów drukowanych"). The innovation was the application of a new reactor construction equipped with regulation-control system of oxidation process using oxygen or oxygen-enriched air.

The project was implemented in close cooperation with Institute of Non Ferrous Metals (IMN) in Gliwice, partner with large experience within construction of aerators used in i.a. flue gas desulphurisation installations, gas dispersion units for process of gypsum production from wastes, or air dispersion units in flotation equipment for non-ferrous metal ores and coal [7-10].

\section{Experimental}

All laboratory and industrial tests of novel method for regeneration of acidic copper(I) and (II) chloride solutions used in printed circuits production technology were performed in IMN Gliwice on order and in close cooperation with company Matusewicz Budowa Maszyn S.A. Innovativeness of the method is mainly due to reactor construction, which is relatively simple. Reactor used in the experiments was composed of rotor and diffuser complex which, at sufficiently high rotor speed, enables very intense mixing and oxygenation of a solution. In order to determine kinetics of $\mathrm{Cu}(\mathrm{I})$ oxidation reaction tests using oxygen, air or oxygenenriched air were performed. Analytical methods for determination of free $\mathrm{HCl}$ (titration method using $\mathrm{NaOH}$ ), monovalent copper (potentiometric method using trivalent $\mathrm{Fe}$ ) and overall copper (redox titration using $\mathrm{KI}$ and $\mathrm{Na}_{2} \mathrm{~S}_{2} \mathrm{O}_{3}$ ) were developed.

\subsection{Laboratory scale tests}

Laboratory tests were carried out using laboratory scale experimental setup (Fig. 1) composed of the following components:

$-3.0 \mathrm{dm}^{3}$ reactor with pneumo-mechanical rotor, made of stainless steel and additionally protected with halar coating, equipped with thermostated heating system and continuous temperature measurement inside a reactor; - oxidising agent supply system (oxygen cylinder, supply with compressed air, reducers, flow meters).

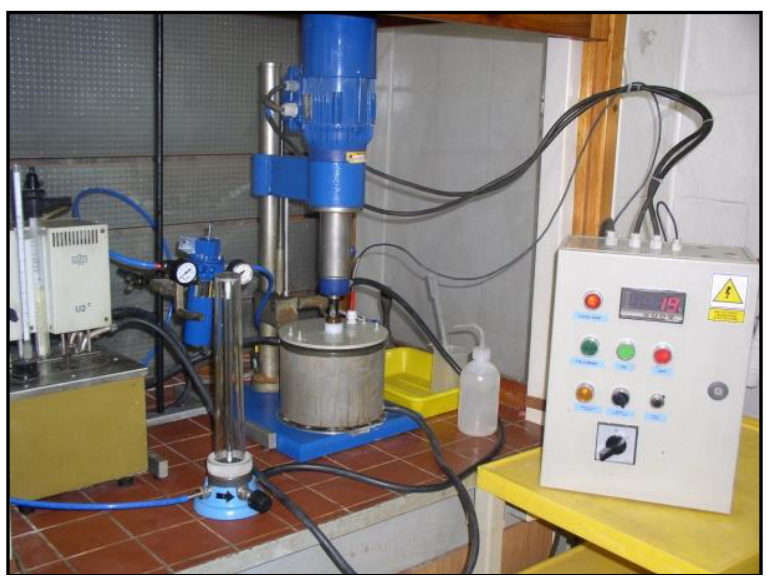

Fig. 1. Laboratory setup for investigation on regeneration of acidic copper chloride solutions.

Table 1 presents the composition of acidic copper chloride solutions used in PCB etching tests.

Table 1. Composition of the solutions used in laboratory tests on regeneration of acidic copper chloride solutions.

\begin{tabular}{|c|c|}
\hline Component & $\begin{array}{c}\text { Concentration, } \\
\mathbf{g}^{/ \mathbf{d m}^{3}}\end{array}$ \\
\hline $\mathrm{Cu}_{\text {overall }}$ & 127.2 \\
\hline $\mathrm{Cu}(\mathrm{II})$ & 126.8 \\
\hline $\mathrm{Cu}(\mathrm{I})$ & 0.44 \\
\hline $\mathrm{HCl}$ & 131.4 \\
\hline
\end{tabular}

The solution was enriched with $\mathrm{Cu}^{+}$ions to the required monovalent copper content of 4.0-5.0 g/dm for the experimental purposes.

Laboratory tests determining $\mathrm{Cu}(\mathrm{I})$ oxidation reaction kinetics using oxygen, air or oxygen-enriched air were performed. Monovalent copper concentration was used for determination of reoxidation rate, i.e. etching solution regeneration rate. Degree of oxygen consumption in each test was also determined. All tests were carried out at set etching solution volume $\mathrm{v}=1,3 \mathrm{dm}^{3}$, at $50^{\circ} \mathrm{C}$. Air was supplied using IMN's compressed air system via reducerfilter system and rotameter with a valve. Air flow rate within $0-600 \mathrm{dm}^{3} / \mathrm{h}$ at rotor rotation rate between 720 $1740 \mathrm{rpm}$ was investigated. Oxygen was supplied to the reactor from a cylinder using reducing valve and rotameter. Oxygen flow rate was between $20-150 \mathrm{dm}^{3} / \mathrm{h}$, while rotor speed was 720-2160 rpm. Air and oxygen streams were mixed at tee placed between rotameter outlets and the reactor. In the tests with oxygen-enriched air mixtures containing $27.3-78.9 \%$ of oxygen were investigated. Air flow rate was between $50-200 \mathrm{dm}^{3} / \mathrm{h}$, oxygen flow rate was in the range $10-140 \mathrm{dm}^{3} / \mathrm{h}$, while rotor speed was constant and equal $1500 \mathrm{rpm}$.

The highest regeneration rate of etching solution was equal to ca. $3.5 \mathrm{~g} \mathrm{Cu}(\mathrm{I}) / \mathrm{min} \cdot \mathrm{dm}^{3}$. It was obtained for oxygen used as an oxidant, at rotor speed of $1500 \mathrm{rpm}$ and oxygen flow rate of $60 \mathrm{dm}^{3} / \mathrm{h}$. Oxygen consumption degree for these conditions was $31.9 \%$. Maximum oxidation rate using air was ca. $0.75 \mathrm{~g} \mathrm{Cu}(\mathrm{I}) / \mathrm{min} \cdot \mathrm{dm}^{3}$ and was achieved at rotor speed of $1200 \mathrm{rpm}$ and air flow rate 
of $100 \mathrm{dm}^{3} / \mathrm{h}$. Oxygen consumption degree for these conditions was only $19.2 \%$. Regeneration rate of etching solution using oxygen-enriched air depends on oxygen partial pressure in oxidising mixture and is situated between results obtained for air and pure oxygen.

Influence of oxidant bubble size on the efficiency of investigated process was also determined. It may have an influence on reoxidation of etching solution. It was assumed that mean bubble size is smaller at large rotor speeds. In the case of oxygen slight influence of bubble size on etching solution regeneration rate was determined.

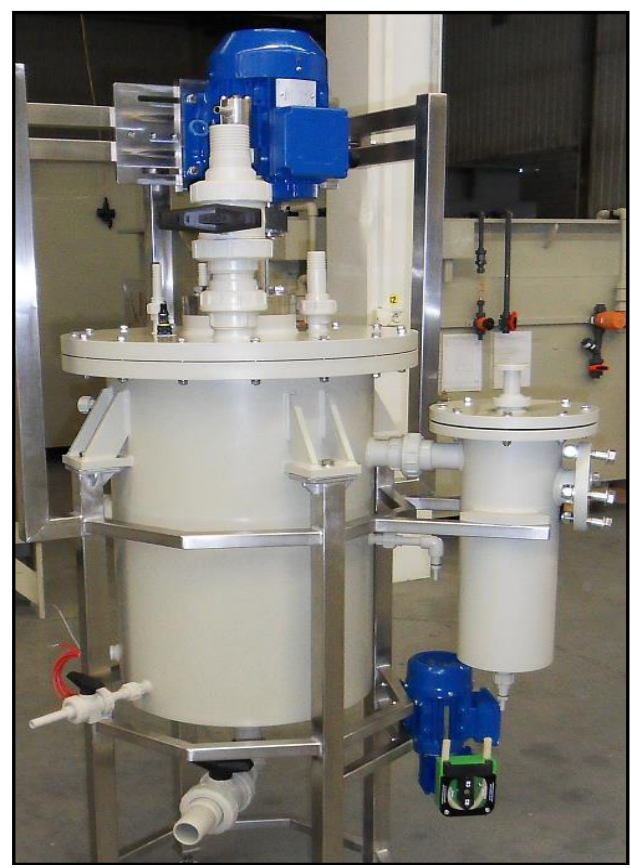

Fig. 2. Reactor of $50 \mathrm{dm}^{3}$ volume used for regeneration of acidic copper chloride solutions.

Relationship between concentrations of monovalent $\mathrm{Cu}$, overall $\mathrm{Cu}, \mathrm{HCl}$ in etching solution and its density, redox potential, electrical conductivity was investigated. Basing on obtained results it was possible to show these dependencies in the form of empirical formulas. Analysis of empirical relationships determined using factorial design $2^{\mathrm{n}}$ type method showed that:

- specific density of chloride etching solution depends mainly on overall $\mathrm{Cu}$ concentration. Influence of $\mathrm{HCl}$ and $\mathrm{Cu}(\mathrm{I})$ concentrations on solution density are 5- and 9-fold lower, respectively;

- redox potential is de facto function of $\mathrm{Cu}(\mathrm{I})$ concentration in the solution only. Influence of other parameters like overall $\mathrm{Cu}$ and $\mathrm{HCl}$ concentrations is ca. 60- and 25-fold weaker;

- coinfluence of investigated factors (solution components) on measured physicochemical parameters is relatively insignificant;
- tests of determined empirical parameters showed, that calculated values are close to measured ones. Mean difference between calculated and measured physicochemical parameters like specific density and redox potential is ca. $1.52 \%$ and $2.8 \%$ of measured value, respectively;

- electrical conductivity of etching solution depends mainly on $\mathrm{HCl}$ concentration. Influence of other component concentrations - overall and monovalent $\mathrm{Cu}-$ is several times smaller;

- verification tests of obtained empirical formula showed that mean difference between measured and calculated value for electrical conductivity is ca. $12 \%$, so is higher than for other investigated parameters of etching solutions.

Based on these equations regulation algorithms for optimum etching solution composition during continuous operation of the reactor were developed.

\subsection{Semi-technical scale tests}

Technical guidelines for the scaled-up reactor construction were based on technological parameters determined during laboratory tests. Constructed semitechnical scale reactor of $50 \mathrm{dm}^{3}$ volume was supplied with gaseous oxygen. Its monovalent copper oxidation rate was $10.5 \mathrm{~kg} / \mathrm{h}$ (Fig. 2). The reactor was also equipped with regulation and control system.

In order to verify determined assumptions of $\mathrm{Cu}(\mathrm{I})$ oxidation process semi-industrial research was performed. It was done using the reactor composed of reaction chamber, aerator with a drive, inlet and outlet stubs, pumps and circulation chamber for measurements of selected physicochemical parameters of solution. The reactor was also equipped with measurement-control system: temperature sensor, electrode for redox potential measurement, electrode for electrical conductivity measurement, sensor of solution level inside a reactor chamber, areometer for solution density measurement and device measuring flow rate of oxygen supplied to the reactor. This measurement-control system allowed to carry out comprehensive technological tests under static and dynamic conditions. Properly situated stubs will allow eventual connection of the reactor to technological line of printed circuits etching.

Technological tests were performed using industrial etching solution, which composition is provided in Table 2. Prior to each test solution composition was modified adjusting monovalent $\mathrm{Cu}$ concentration to 2.0-2.5 g/ $\mathrm{dm}^{3}$. Divalent $\mathrm{Cu}$ concentration was maintained in the range $160-190 \mathrm{~g} / \mathrm{dm}^{3}$, while $\mathrm{HCl}$ concentration was constant and equal to ca. $6.1 \mathrm{~g} / \mathrm{dm}^{3}$. NaCl concentration was not adjusted assuming that it remained close to initial value during the course of the process. 


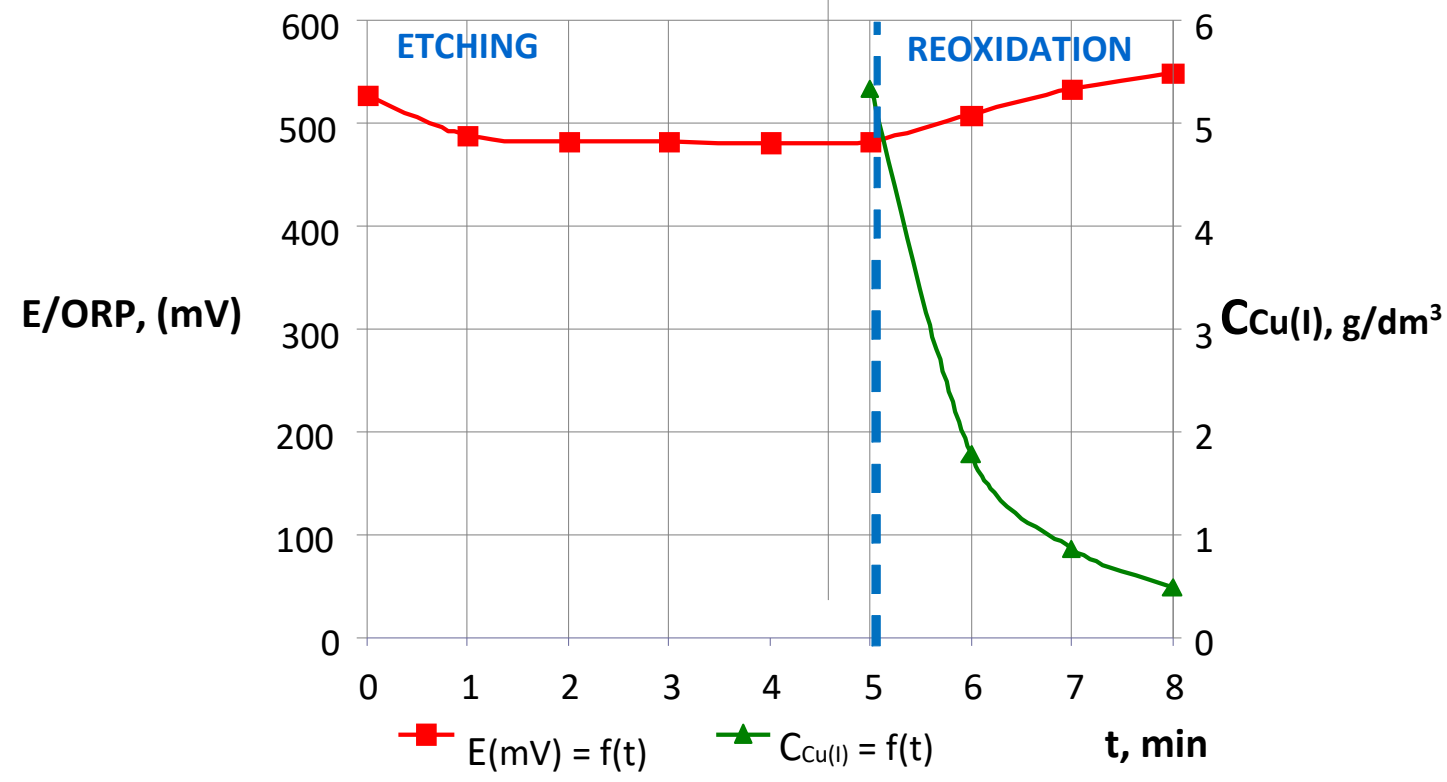

Fig. 3. Course of solution etching and regeneration process using oxygen in $50 \mathrm{dm}^{3}$ reactor.

Table 2. Composition of the solutions used in semi-technical test of acidic copper chlorides solution regeneration.

\begin{tabular}{|c|c|}
\hline Component & $\begin{array}{c}\text { Concentration, } \\
\mathbf{g}^{\mathbf{d} \mathbf{d m}^{\mathbf{3}}}\end{array}$ \\
\hline $\mathrm{Cu}_{\text {overall }}$ & 181.3 \\
\hline $\mathrm{Cu}(\mathrm{II})$ & 126.8 \\
\hline $\mathrm{Cu}(\mathrm{I})$ & 0.12 \\
\hline $\mathrm{HCl}$ & 6.1 \\
\hline $\mathrm{NaCl}$ & 123.9 \\
\hline
\end{tabular}

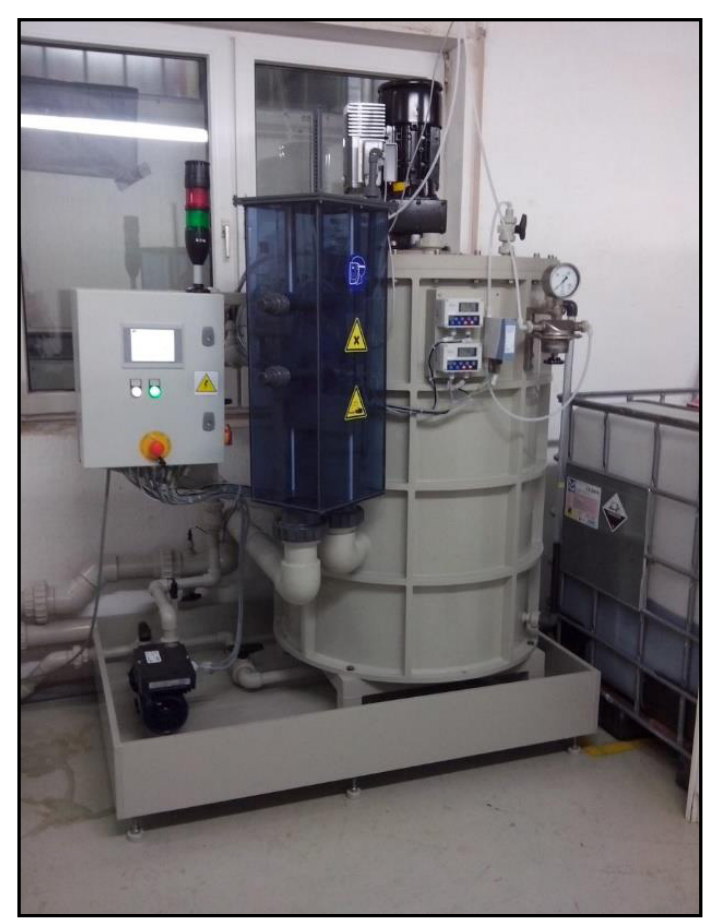

Fig. 4. The technical scale reactor for acidic copper chloride solutions regeneration.
Test series for two different positions of circulation holes (closed and open) were performed. Different rotor speeds $(650,800$ and $950 \mathrm{rpm})$ in the reactor were applied. Constant overpressure of 40 mbar and solution temperature of $50-55{ }^{\circ} \mathrm{C}$ inside the reactor were maintained during each test. Obtained results confirmed the process efficiency obtained during laboratory tests. Exemplary course of solution etching and regeneration (oxidation) process during performed tests is shown in Fig. 3. Optimum parameters for the periodic process using the reactor and industrial solution were selected:

- open circulation holes;

- rotor speed ca. $800 \mathrm{rpm}$;

- process temperature $50-55^{\circ} \mathrm{C}$.

For these conditions, in time interval 0-2 min, the solution regeneration rate (monovalent $\mathrm{Cu}$ oxidation) was ca. 0.84 $\mathrm{g} \mathrm{Cu}(\mathrm{I}) / \mathrm{min} \cdot \mathrm{dm}^{3}$.

\subsection{Technical scale tests}

Technical guidelines for technical scale reactor construction were based on optimum parameters of acidic copper chloride solution regeneration process determined during semi-technical scale tests. The reactor of $0.5 \mathrm{~m}^{3}$ volume and estimated monovalent copper oxidation rate of $20 \mathrm{~kg} / \mathrm{h}$ was constructed (Fig. 4).

Basing on analysis of semi-technical scale tests results manual of reactor preparation for application tests under industrial conditions was developed. The scope of the manual covered:

- operational parameters of the reactor (rotor speed, operational volume, volume of gas phase and oxygen pressure, solution flow rate, solution temperature, density of regenerated solution);

- adaptation of the reactor to industrial conditions incorporation of the reactor into technological line of printed circuits etching;

- pressure closure of the reactor;

*Corresponding author: dorotak@imn.gliwice.pl 
- air removal from the reactor chamber;

- technological start-up of the reactor;

- reactor shut-down;

- regulation of the reactor;

Application tests of the $0.5 \mathrm{~m}^{3}$ reactor confirmed assumed regeneration rates of etching solutions used in PCB production. The reactor possesses 9 th technological readiness level (TRL 9). It means that it is ready for direct implementation in industrial practice.

\section{Summary}

The result of long-standing cooperation between Institute of Non-Ferrous Metals and company Matusewicz Budowa Maszyn S.A. is development of economic, environmentally-friendly and innovative method for regeneration of acidic copper chloride solution generated during printed circuits etching process. New construction of a reactor equipped with regulation and control system of oxidation process allows effective circulation of oxidant during the process. It allows to maximize oxygen utilisation rate during monovalent copper oxidation and desired efficiency and rate of etching solution regeneration process. The advantages of the process are simplification of $\mathrm{Cu}(\mathrm{I})$ oxidation process, elimination of expensive and often toxic and harmful reagents, stable process parameters, no copper loss and wastes elimination. The additional advantage is low construction and operating costs of the reactor.
Experiments were performed within the project POIG.01.04.0002-049/11 „Opracowanie nowej metody regeneracji kwaśnych roztworów chlorku miedziowego stosowanych w procesie trawienia obwodów drukowanych" granted by PARP in a Program Innowacyjna Gospodarka.

\section{References}

1. D. M. Allen, H.J.A. White, Processing of Advanced Materials, 2, 19-24 (1992)

2. Robertson, Robertson's Chemicals Ltd., (1986)

3. Werner D. Bissinger, US Patent no: 46966717 (1987)

4. A. Stehlik, US Patent no: 4396475 (1983)

5. S. J. Beyer, R. M. Lukes, US Patent no: 3794571 (1974)

6. P. J. Jefferies, $P h D$ Thesis, Cranfield University (2005)

7. J. Mrozowski et al. - Spr. IMN nr 6231/06 (unpublished) (2006)

8. J. Mrozowski et al. - Projekt kluczowy POIG.01.03.01-24-019/08-00 - Spr. IMN nr 7012/2012 (unpublished) (2012)

9. W. Wasilewski et al. PL Patent no: 209175 (2006)

10. J. Mrozowski, W Wasilewski, A. Chmielarz, R. Kurowski, PL Patent no: 201034 (2005) 